\title{
Ein neues Brenthidengenus \\ aus dem Naturhistorischen Museum zu Jübeck.
}

Von R. Kleine, Stettin.

(Mit 3 Abbildungen.)

Allacompsus gen. nov. (Belopheridarum).

$\alpha \lambda \lambda_{\eta}=$ anders $x_{\mu} \mu \psi o_{S}$ geschmückt, wegen der abweichenden

Schmuckzeichnung auf den Decken.

$\sigma^{7}$. Von mittlerer Statur. Kopf etwa so lang wie hinter den Augen breit, nach vorn etwas verschmälert, Hinterrand gerade, Hinterecken gerundet, Oberseite gewölbt, auf dem Scheitel zart gefurcht, Unterseite mit punktartiger Gulargrube, undeutlicher Mittelfurche und schwachem Warzenbesatz. Augen grols, fast der ganzen seitlichen Kopf einnehmend, aber den Hinterrand desselben nicht erreichend, halbkugelig, märsig prominent.

Metarostrum länger wie der Kopf, aber höchstens halb so lang wie das Prorostrum, rundlich walzig mit flacher, schmaler Mittelfurche, Oberseite glatt, Seiten und Unterseite einzeln warzig skulptiert. Mesorostrum am Metarostrum verengt, dann erweitert, aber nicht so breit wie das Metarostrum, mit kräftiger Mittelfurche, Seitenränder nach oben aufgebogen; Unterseite stärker erweitert, mit kräftigem Mittelkiel, ohne warzige Skulptur. Prorostrum oberseits im basalen Drittel sehr schmal, platt, Oberkanten bucklig-warzig. An der schmalsten Stelle fällt die Oberseite nach unten $a b$, erweitert sich um die mehrfache Breite und nimmt nach vorn noch etwas, aber wenig, an Breite zu. Seitenkanten mit einzelstehenden Dornen, deren erster am längsten ist, diese ganze Fläche warzig skulptiert; Seiten mit derselben Skulptur; Unterseite nicht verschmälert, gekielt, der Kiel in der Vorderrandspartie in eine Furche übergehend, keine Skulptur. Vorderrand schwach nach innen gebogen, Mandibeln klein.

Fühler fast bis zum Deckenhinterrand reichend, 1. Glied nach vorn stark keulig erweitert, nach unten scharfkantig, die cante grob gezahnt, 2. am kürzesten, ebenfalls mit scharfer Kante und kräftiger Bezahnung, 3. desgleichen, die folgenden rundlich-kegelig, das 4. an der Basis noch schwach gezahnt, 4.-3. etwa gleich lang, 9. und 10. verkürzt, 11. lang, allmählich zugespitzt; alle Glieder fest aneinandergefügt.

Prothorax eiförmig, Oberseite \pm flach mit ganz obsoleter Mittelfurche, Halsring scharf abgesetzt; postcoxaler Teil des Prosternums sehr kurz, Hüftringe mälsig stark.

Elytren von Thoraxbreite, Basis gerade, Seiten nach hinten allmählich verschmälert, Aufsenecken strmpf-spitzig, Hinterrand 
gerade, gitterfurchig, 2., 3. und 5. Rippe auf der Mitte schmal, alle anderen breit, Suturalfurche ungegittert, aber \pm deutlich punktiert, Schmuckzeichnung vorhanden.

Hautfügel nach dem Arrhenodini-Typus gebaut.

Beine schlank. Schenkel lang mit schmächtiger Keule, im vordeřen Viertel gedornt, Schienen gerandet, walzig gerundet, 1. Tarsenglied das längste von allen, Klauenglied grols, normal.

Metasternum nur vor dem Abdomen mit tiefer Punktgrube, Abdomen ungefurcht, Quernaht zwischen dem 1. und 2. Segment deutlich.

Passiver Stridulationsapparat mit erhabener Trennungslinie. Skulptur von dieser bis gegen den Rand ans Hexaêdern bestehend, die in der Behaarung des Aufsenrandes verschwindet; aktiver Teil ohne besondere Merkmale.

Typus der Gattung: A. separator n. sp.

\section{Allacompsus separator n. sp.}

Hellschokoladebraun, irdenfarbig, Halsring, Fühlerglieder an den Enden und die Schenkel an der Basis in geringem Umfang

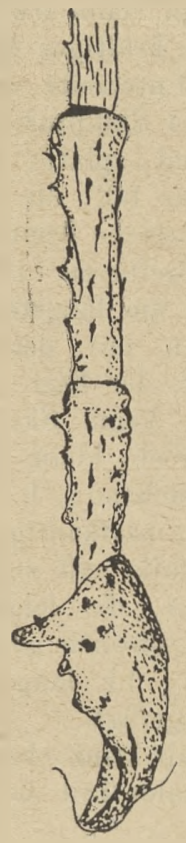

Abb. 1.

Basale Füblerglieder.

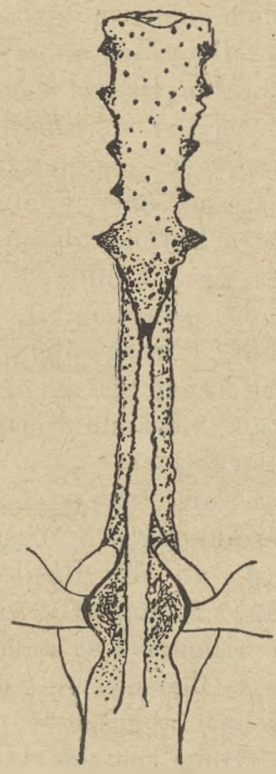

Abb. 2.

Prorostrum.

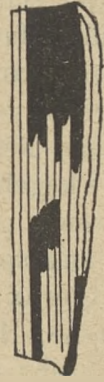

Abb. 3.

Deckenzeichnung von All. separator n. sp. 
geschwärzt, Schmuckzeichnung schmutzig gelb, Oberseite mit Ausnahme des vorderen Rüsselteiles und der Schmuckzeichnung matt, Unterseite und Extremitäten hochglänzend. Kopf und Prothorax ohne Skulptur. Auf den Elytren die Rippen unpunktiert. Lage der Schmuckzeichnung: an der Basis Rippe 3-8 mit 土 langen Streifen, die auf 6 und 8 an längsten sind, im Absturzteil: langer Streifen auf 3 im hinteren Drittel bis zum Rand, 4-6 kurzer Streifen hinter der Mitte, auf 9 kurzer Apicalstreifen. Hinterschenkel auf der Aufsenseite mit tiefen, starken Querrunzeln, Körperunterseite unskulptiert.

Länge (total): 22,5 mm, Breite (Thorax): 4,0 mm zirka.

Heimat: Cocos-Inseln.

Typus im Lübecker Museum.

Die Gattung ist mit keiner anderen der Belopherini zu vergleichen, steht vielleicht meiner neuen Megateras von Borneo durch den Bau des Rüssels und der Fühler am nächsten. Während bei jener Gattung die Anlage der Schmuckzeichnung genau nach dem Grundschema der Arrhenodini und Belopberini angelegt ist, ist die Anordnung bei Allacompsus bisher bei Arrhenodini und Belopherin noch nicht bekannt gewesen. Dieser Umstand und die ganz merkwürdige Grundfärbung ist wahrscheinlich auf die Isolierung z.urückzuführen.
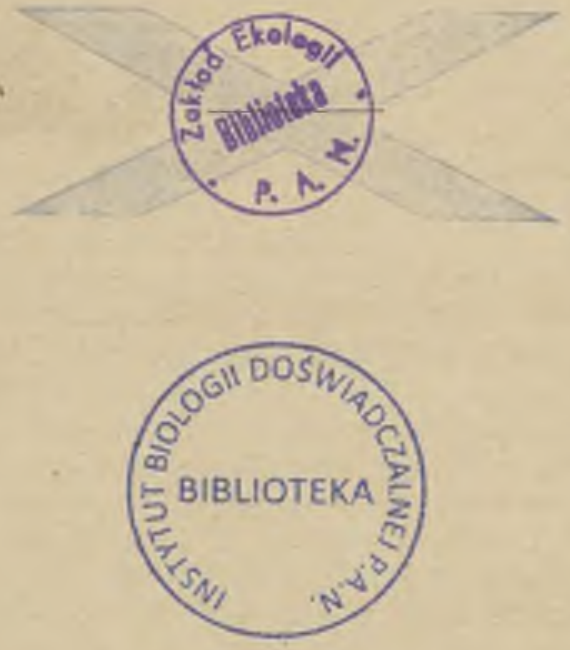
